\title{
Nocturnal periodic breathing in primary pulmonary hypertension
}

\author{
R. Schulz, G. Baseler, H.A. Ghofrani, F. Grimminger, H. Olschewski, W. Seeger
}

\begin{abstract}
Nocturnal periodic breathing in primary pulmonary hypertension. $R . \quad$ Schulz, G. Baseler, H.A. Ghofrani, F. Grimminger, H. Olschewski, W. Seeger. (C)ERS Journals Ltd 2002.

ABSTRACT: Cheyne-Stokes respiration is frequently observed in congestive heart failure. Among other factors, prolongation of circulation time, hypocapnia and hypoxia are thought to underlie this sleep-related breathing disorder. Primary pulmonary hypertension (PPH) is also characterized by reduced cardiac output and blood gas alterations. Therefore, the aim of the present study was to determine whether a nocturnal periodic breathing (PB) occurs in $\mathrm{PPH}$.

A total of 20 consecutive patients with PPH who had been admitted for pharmacological investigation of pulmonary vasoreactivity were investigated by lung function testing, right heart catheterization and full-night attended polysomnography.

PB was detected in six patients $(30 \%)$ (mean \pm SEM: apnoea/hypopnoea index $37 \pm 5 \mathrm{~h}^{-1}$; arterial oxygen saturation was $<90 \%$ during $56 \pm 6.5 \%$ of total sleep time). The patients with $\mathrm{PB}$ had more severe haemodynamic impairment than those without. They also had a more marked reduction in the pulmonary diffusion capacity and greater arterial hypoxia. PB was markedly improved or even eradicated by nasal oxygen during the night.

Periodic breathing occurs in patients with advanced primary pulmonary hypertension and can be reversed by nocturnal nasal oxygen. The clinical and prognostic significance of periodic breathing in primary pulmonary hypertension needs to be determined by further studies.

Eur Respir J 2002; 19: 658-663.
\end{abstract}

\begin{abstract}
Division of Pulmonary \& Critical Care Medicine, Dept of Internal Medicine, Justus-Liebig-University, Gießen,
\end{abstract} Germany.

Correspondence: R. Schulz

Division of Pulmonary \& Critical Care Medicine

Dept of Internal Medicine

Justus-Liebig-University

Klinikstr. 36

35392 Gießen

Germany

Fax: 496419942529

E-mail: Richard.Schulz@innere.med.unigiessen.de

Keywords: Primary pulmonary

hypertension

sleep disordered breathing

Received: March 142001

Accepted after revision October 27 2001
Primary pulmonary hypertension $(\mathrm{PPH})$ is a rare disorder of the pulmonary arteries which predominantly affects young and middle-aged females and carries a very poor prognosis [1]. By definition the aetiology of PPH is unknown and its diagnosis thus relies on exclusion criteria [2]. Treatment of PPH is based on vasodilator therapy, oral anticoagulation and supplemental oxygen $\left(\mathrm{O}_{2}\right)$ [3]. Further therapeutic options are atrial septostomy and lung transplantation $[4,5]$.

Cheyne-Stokes respiration (CSR) is a specific form of periodic breathing (PB) which can be observed in the setting of congestive heart failure (CHF) [6]. It occurs in $\sim 50 \%$ of patients with a left ventricular ejection fraction of $<40 \%[7,8]$. The pathophysiology of CSR has not yet been fully clarified [9]. However, it is assumed that reduction of cardiac output resulting in a prolonged circulation time from the lung to the chemoreceptors plays an important role $[10,11]$. Decreased blood oxygen tension stimulates the discharge of peripheral chemoreceptors and gives rise to the characteristic crescendo-decrescendo hyperventilation pattern of CSR [12]. Conversely, hyperventilation-induced hypocapnia sets the stage for recurrent apnoeas by shifting the hypercapnic ventilatory response to the apnoea threshold for carbon dioxide $\left(\mathrm{CO}_{2}\right)$ [13, 14]. Finally, increased respiratory drive to hypercapnia and decreased body stores of $\mathrm{O}_{2}$ and $\mathrm{CO}_{2}$ are presumed to contribute to the development of CSR in CHF $[15,16]$.

In advanced PPH profound abnormalities in the haemodynamics and gas exchange parameters may be found. Due to the increased pulmonary artery pressure and pulmonary vascular resistance, cardiac output is likely to be depressed. Together with ventilation-perfusion mismatching this low output syndrome leads to hypoxaemia.

Finally, to compensate for hypoxaemia, hyperventilation and consequent hypocapnia develops. Thus, the same basic mechanisms presumed to underlie CSR in CHF might apply in PPH. However, the characteristics of sleep and breathing in PPH have not previously been reported. Therefore, the aim of the present study was to determine if sleep-disordered breathing is also seen in PPH.

\section{Patients and methods}

\section{Patients}

A total of 20 patients with PPH were investigated. All had been admitted consecutively for right heart catheterization and pharmacological testing of pulmonary vasoreactivity. To participate in the study, they had to be in a stable clinical condition (as defined by 
New York Heart Association classes) within the previous 4 weeks. Furthermore, it was requested that no changes in medical therapy had occurred during that time period. Exclusion criteria were acute disease states such as infection or progressive cardiac failure and the presence of sleep-related breathing disorders other than PB (i.e. obstructive sleep apnoea). Prior to participation each patient gave informed written consent and the study was approved by the local ethics committee.

\section{Lung function tests}

The forced expiratory volume in one second and vital capacity ( $\%$ predicted, normal values: $>80 \%)$ were measured, together with the pulmonary carbon monoxide diffusing capacity $(D \mathrm{~L}, \mathrm{CO})$ by the single breath-holding method ( $\%$ pred, normal value: $>80 \%$ ) and awake arterial blood gases.

\section{Right heart catheterization}

In all patients a Swan-Ganz triple-lumen thermodynamic catheter was inserted via a transjugular or transfemoral venous approach as described previously [17-19]. The following haemodynamic parameters were determined with the normal range indicated in brackets: mean pulmonary artery pressure $(<20 \mathrm{mmHg}$ at rest); pulmonary capillary wedge pressure $(5-10 \mathrm{mmHg}) ;$ pulmonary vascular resistance $\left(<250 \mathrm{dyn} \cdot \mathrm{s}^{-1} \cdot \mathrm{cm}^{-5}\right)$; cardiac output $(\mathrm{CO}, 5.0$ $\left.8.0 \mathrm{~L} \cdot \mathrm{min}^{-1}\right)$; cardiac index $\left(\mathrm{CI}, 2.5-4.0 \mathrm{~L} \cdot \mathrm{min}^{-1} \cdot \mathrm{m}^{-2}\right)$; right ventricular ejection fraction $(60-70 \%)$.

\section{Sleep studies}

Prior to polysomnography, all patients were interviewed about their sleep pattern and the Epworth Sleepiness Scale (ESS) was used to evaluate daytime sleepiness [20]. At night, the electroencephalogram (electrodes at positions $\mathrm{C} 3-\mathrm{A} 2$ and $\mathrm{C} 4-\mathrm{A} 1$ of the international 10-20 system), electrooculogram and electromyogram of the submental and pretibial muscles; airflow at the nose and mouth by thermistors; thoracoabdominal movements by inductance plethysmography; the arterial oxygen saturation $\left(\mathrm{Sa}_{\mathrm{a}} \mathrm{O}_{2}\right)$ with pulse oximetry at the finger; and an electrocardiogram were obtained.

All data were recorded on a computerized polysomnograph with the capacity for analogue registration (Sidas GS, Institut für Medizintechnik, $\mathrm{GmbH}$, Wettenberg, Germany). An obstructive apnoea was diagnosed if complete cessation of oronasal flow occurred in the presence of thoracoabdominal breathing movements. If neither oronasal flow nor breathing efforts of the chest and abdomen could be detected the apnoea was scored as central. Hypopnoea was defined as a reduction in the respiratory amplitude of $>50 \%$ compared to the preceding signals. All apnoeas and hypopnoeas were required to have a duration of at least $10 \mathrm{~s}$. The apnoea/hypopnoea index (AHI) was obtained by dividing the total number of apnoeas and hypopnoeas through the total sleep time (TST). An AHI of $>10 \mathrm{~h}^{-1}$ of sleep was considered to be diagnostic of sleep-disordered breathing.

$\mathrm{PB}$ was required to show a crescendo-decrescendo pattern of hyperventilatory phases between central apnoeas or hypopnoeas (at least three consecutive cycles). In addition to the AHI, the duration of PB was expressed as per cent of TST. Lung-to-finger circulation time (LFCT) was measured from the first breath after a central apnoea to the subsequent nadir of $\mathrm{Sa}_{\mathrm{a}} \mathrm{O}_{2}$. An average of 10 randomly selected apnoeas, during nonrapid eye movement (NREM) sleep when $\mathrm{Sa}_{\mathrm{a}} \mathrm{O}_{2}$ fell sufficiently to allow determination of the $\mathrm{Sa}_{\mathrm{a}} \mathrm{O}_{2}$ nadir, was taken. Cycle length was measured as the time from the first breath following a central apnoea to the first breath after the following apnoea on the same cycle used to determine LFCT. Cycle length was calculated as the sum of the duration of hyperpnoea and apnoea.

Sleep was staged manually in 30-s intervals according to the criteria of RECHTSCHAFFEN and KALES [21]. Arousals were scored following the American Sleep Disorders Association criteria [22].

At the time of the investigation, 10 of the 20 patients were receiving long-term oxygen therapy (LTOT). The indication for LTOT in the PPH patients was a daytime oxygen tension in arterial blood $\left(\mathrm{Pa}, \mathrm{O}_{2}\right)<8 \mathrm{kPa}$. Because oxygen administration has been reported to suppress CSR in CHF [23, 24], polysomnography was performed while breathing room air in all patients.

\section{Statistical analysis}

If not otherwise indicated, all data are presented as mean \pm SEM. Patients with and without $\mathrm{PB}$ were compared by analysis of variance (ANOVA). This was performed for several parameters (i.e. blood gases, lung function, haemodynamics and polysomnographical variables). Treatment effects were evaluated by a paired t-test. A p-value $<0.05$ was considered as statistically significant.

\section{Results}

The patient characteristics are summarized in tables 1 and 2. The majority of the patients in this study were young females. Almost all were on oral anticoagulation and more than one-half had already received vasodilator therapy, i.e. calcium-channel blockers or inhalative prostanoids (iloprost (ilome$\operatorname{din}($, Fa.; Schering, Berlin, Germany) at a daily cumulative dose of 50-100 $\mu \mathrm{g}$ ). On average, arterial blood gas analysis showed pronounced hypocapnia and moderate hypoxia. The pulmonary diffusing capacity was markedly diminished, whereas ventilatory parameters were normal. The patients suffered from severe precapillary pulmonary hypertension with increased pulmonary vascular resistance but normal capillary-wedge pressures. As a result of 
Table 1.-Anthropometric data, New York Heart Association (NYHA) classes and treatment

\begin{tabular}{lc}
\hline Subjects n & 20 \\
Sex M:F & $3: 17$ \\
Age yrs means \pm SEM & $45 \pm 2.9$ \\
BMI kg.m ${ }^{-2}$ means \pm SEM & $23.5 \pm 1.1$ \\
NYHA class & \\
I & $8(40)$ \\
II & $10(50)$ \\
III & $2(10)$ \\
IV & $18(90)$ \\
Oral anticoagulation & $11(55)$ \\
Calcium-channel blockers & $12(60)$ \\
Long-term prostanoid therapy & $11(55)$ \\
Diuretics & $10(50)$ \\
LTOT &
\end{tabular}

Data are presented as $\mathrm{n}(\%)$ unless otherwise stated. BMI: Body mass index; LTOT: long-term oxygen treatment; M: male; F: female.

right-ventricular dysfunction $\mathrm{CO}$ and $\mathrm{CI}$ were markedly reduced.

PB was detected in six of the 20 patients $(30 \%)$. The results of polysomnography are given in detail in table 3. PB occurred predominantly during phases of NREM $1+2$ sleep and was characterized by more hypopnoeas than apnoeas. The patients with PB had severe nocturnal $\mathrm{O}_{2}$ desaturation. On average, the distribution of sleep stages was normal and the number of arousals was moderately increased. Consequently, only two patients complained of sleeprelated symptoms including difficulty in falling asleep, nocturnal awakening with dyspnoea and daytime fatigue. An example of a polysomnographical recording of PB observed in a patient with PPH is shown in figure 1.

The characteristics of the patients with and without PB are compared in table 4. All three male patients investigated suffered from $\mathrm{PB}$. The mean age was similar in the patients with and without $\mathrm{PB}$. The carbon dioxide tension in arterial blood $\left(\mathrm{Pa}_{\mathrm{a}} \mathrm{CO}_{2}\right)$ values were not significantly different between the

Table 2.-Arterial blood gases, lung function and haemodynamic data

\begin{tabular}{lr}
\hline Subjects n & \\
$P \mathrm{a}, \mathrm{O}_{2} \mathrm{kPa}$ & 20 \\
$\mathrm{P}_{1}, \mathrm{CO}_{2} \mathrm{kPa}$ & $8.8 \pm 0.4$ \\
$\mathrm{FEV} \%$ pred & $3.9 \pm 0.1$ \\
$\mathrm{VC} \% \mathrm{pred}$ & $88.0 \pm 3.3$ \\
$D \mathrm{~L}, \mathrm{CO} \% \mathrm{pred}$ & $91.7 \pm 3.3$ \\
$\mathrm{PAP} \mathrm{mmHg}$ & $62.4 \pm 4.8$ \\
$\mathrm{PVR} \mathrm{dyn} \cdot \mathrm{s}^{-1} \cdot \mathrm{cm}^{-5}$ & $56 \pm 2.7$ \\
$\mathrm{PCWP} \mathrm{mmg}^{-1}$ & $1369 \pm 133$ \\
$\mathrm{CO} \mathrm{L} \cdot \mathrm{min}^{-1}$ & $5 \pm 0.4$ \\
$\mathrm{CI} \mathrm{L} \cdot \mathrm{min}^{-2} \cdot \mathrm{m}^{-2}$ & $3.31 \pm 0.2$ \\
$\mathrm{RVEF} \%$ & $1.96 \pm 0.1$ \\
\hline
\end{tabular}

Data are presented as mean \pm SEM. $C I$ : cardiac index; CO: cardiac output; $D$ L,CO: pulmonary diffusion capacity for carbon monoxide; FEV1: forced expiratory volume in one second; PAP: pulmonary artery pressure; $\mathrm{Pa}_{\mathrm{a}} \mathrm{CO}_{2}$ : arterial partial pressure of carbon dioxide; PCWP: pulmonary capillary wedge pressure; $\mathrm{Pa}_{\mathrm{a}, \mathrm{O}_{2}}$ : arterial partial pressure of oxygen; PVR: pulmonary vascular resistance; RVEF: right ventricular ejection fraction; $\mathrm{VC}$ : vital capacity.
Table 3. - Polysomnographical data of patients with $(+)$ and without $(-)$ periodic breathing (PB)

\begin{tabular}{lrcc}
\hline & PB + & PB - & p-value \\
\hline Patients n & 6 & 14 & \\
ESS & $8.8 \pm 1.0$ & $6.0 \pm 1.4$ & NS \\
AHI n $h^{-1}$ & $37 \pm 4.7$ & $9 \pm 2.6$ & $<0.01$ \\
$\mathrm{HI} \cdot \mathrm{h}^{-1}$ & $23 \pm 3.2$ & $6 \pm 1.1$ & $<0.01$ \\
PB \% of TST & $38 \pm 5.8$ & & \\
LFCT s & $50 \pm 2.0$ & & \\
Cycle length s & $59 \pm 4.9$ & & \\
Mean $\mathrm{Sa}_{\mathrm{a}} \mathrm{O}_{2} \%$ & $88.5 \pm 0.5$ & $91.9 \pm 0.6$ & $<0.05$ \\
Lowest $\mathrm{Sa}_{2} \%$ & $77 \pm 1.0$ & $81 \pm 1.7$ & $\mathrm{NS}$ \\
Sa, $\mathrm{O}_{2}<90 \% \%$ of TST & $56 \pm 6.5$ & $20 \pm 6.7$ & $<0.01$ \\
NREM 1+2 \% of TST & $57 \pm 1.6$ & $55 \pm 2.2$ & $\mathrm{NS}$ \\
NREM 3+4 \% of TST & $28 \pm 1.6$ & $30 \pm 2.5$ & $\mathrm{NS}$ \\
REM \% of TST & $15 \pm 1.8$ & $15 \pm 1.8$ & $\mathrm{NS}$ \\
Sleep efficiency \% of TIB & $76 \pm 4.2$ & $73 \pm 4.2$ & NS \\
Arousal index n $\mathrm{h}^{-1}$ & $26 \pm 1.8$ & $11 \pm 2.2$ & $<0.01$ \\
\hline
\end{tabular}

Data are presented as mean \pm SEM. AHI: apnoea/hypopnoea index; ESS: Epworth Sleepiness Scale; HI: hypopnoea index; LFCT: lung to finger circulation time; NREM: nonrapid eye movement sleep; PB: periodic breathing; REM: rapid eye movement sleep; $\mathrm{S}_{\mathrm{a}, \mathrm{O}_{2}}$ : oxygen saturation; TIB: time in bed; TST: total sleep time; NS: nonsignificant.

two patient groups but those with $\mathrm{PB}$ had more pronounced hypoxaemia than those with a normal breathing pattern. Patients with nocturnal PB had a lower $D$ L,CO than those without. Patients showing PB had a higher pulmonary artery pressure and pulmonary vascular resistance and also more severely depressed right ventricular function.

Five out of the six patients with $\mathrm{PB}$ agreed to use nasal $\mathrm{O}_{2}$ during a second night and to be re-examined by polysomnography. $\mathrm{O}_{2}$ was administered at a constant flow of $2 \mathrm{~L} \cdot \mathrm{min}^{-1}$ via nasal prongs. As shown in figure 2, four of these five patients responded with almost complete resolution of the $\mathrm{PB}$, i.e. a decrease of the AHI to $<10 \mathrm{~h}^{-1}$. In one patient, $\mathrm{O}_{2}$ had no beneficial effect on nocturnal PB. The sleep architecture

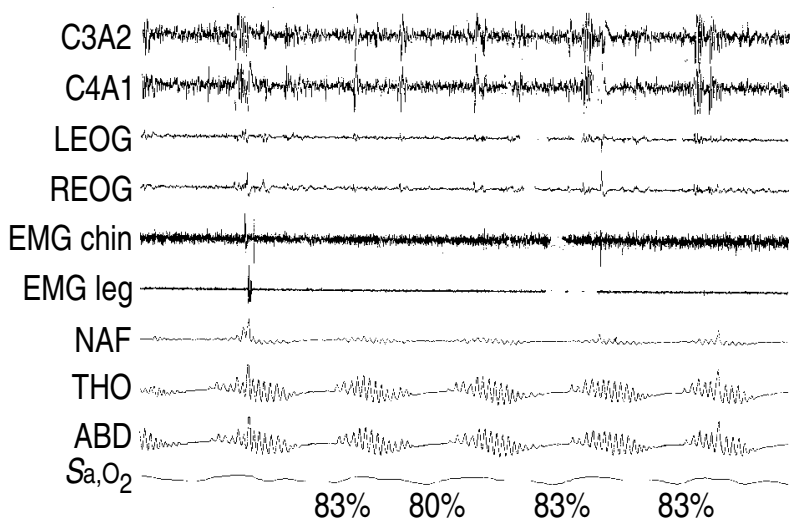

Fig. 1.-5-min polysomnographical recording of periodic breathing observed in a patient with primary pulmonary hypertension. C3A2/C4A1: electroencephalographic positions of the international 10-20 system; LEOG: left electrooculogram; REOG: right electrooculogram; EMG: submental and pretibial electromyogram; NAF: nasal airflow; THO/ABD: thoracoabdominal breathing movements; $\mathrm{Sa}_{\mathrm{a}, \mathrm{O}_{2}}$ : arterial oxygen saturation. 
Table 4. - Anthropometric data, lung function and haemodynamic parameters of the patients with $(+)$ and without $(-)$ periodic breathing (PB)

\begin{tabular}{|c|c|c|c|}
\hline & $\mathrm{PB}+$ & PB - & p-value \\
\hline Patients n & 6 & 14 & \\
\hline Sex M:F n & $3: 3$ & $0: 14$ & $<0.01$ \\
\hline Age yrs & $43 \pm 3.6$ & $45 \pm 2.6$ & NS \\
\hline $\mathrm{BMI} \mathrm{kg} \cdot \mathrm{m}^{-2}$ & $21.5 \pm 0.7$ & $24.4 \pm 1.4$ & NS \\
\hline$P \mathrm{a}, \mathrm{O}_{2} \mathrm{kPa}$ & $6.6 \pm 0.9$ & $9.1 \pm 0.7$ & $<0.05$ \\
\hline$P \mathrm{a}, \mathrm{CO}_{2} \mathrm{kPa}$ & $3.9 \pm 0.2$ & $3.9 \pm 0.1$ & NS \\
\hline FEV1 $\%$ pred & $91.5 \pm 6.8$ & $86.5 \pm 3.7$ & NS \\
\hline VC \% pred & $90.8 \pm 8.1$ & $92.0 \pm 3.4$ & NS \\
\hline$D \mathrm{~L}, \mathrm{CO} \%$ pred & $57.1 \pm 4.5$ & $69.6 \pm 3.5$ & $<0.05$ \\
\hline PAP mmHg & $63 \pm 2.4$ & $53 \pm 3.7$ & $<0.05$ \\
\hline PVR dyn $\cdot \mathrm{s} \cdot \mathrm{cm}^{-5}$ & $1951 \pm 149$ & $1119 \pm 134$ & $<0.05$ \\
\hline PCWP mmHg & $6 \pm 0.4$ & $5 \pm 0.7$ & NS \\
\hline $\mathrm{CO} \mathrm{L} \cdot \mathrm{min}^{-1}$ & $2.39 \pm 0.1$ & $3.71 \pm 0.3$ & $<0.01$ \\
\hline $\mathrm{CI} \mathrm{L} \cdot \mathrm{min} \cdot \mathrm{m}^{-2}$ & $1.38 \pm 0.1$ & $2.21 \pm 0.2$ & $<0.01$ \\
\hline RVEF \% & $7 \pm 0.8$ & $20 \pm 2.4$ & $<0.01$ \\
\hline
\end{tabular}

Data are presented as means \pm SEM unless otherwise stated. NS: nonsignificant; $\mathrm{m}$ : male; f: female; BMI: body mass index; $P \mathrm{a}, \mathrm{O}_{2}: \mathrm{O}_{2}$ tension in arterial blood; $P \mathrm{a}, \mathrm{CO}_{2}: \mathrm{CO}_{2}$ tension in arterial blood; FEV1: forced expiratory volume in one second; VC: vital capacity; $D \mathrm{~L}, \mathrm{CO}$ : pulmonary diffusion capacity for carbon monoxide; PAP: pulmonary artery pressure; PVR: pulmonary vascular resistance; CO: cardiac output; CI: cardiac index; RVEF: right ventricular ejection fraction; PCWP: pulmonary capillary wedge pressure.

was not significantly changed by $\mathrm{O}_{2}$ therapy in these subjects (data not shown).

\section{Discussion}

In six of the 20 patients studied nocturnal PB closely resembling CSR in CHF was observed. PB occurred predominantly during NREM stages $1+2$ sleep and was associated with considerable nocturnal $\mathrm{O}_{2}$ desaturation. The overall distribution of sleep stages was normal and there was only a moderate increase in the number of apnoea-related arousals.

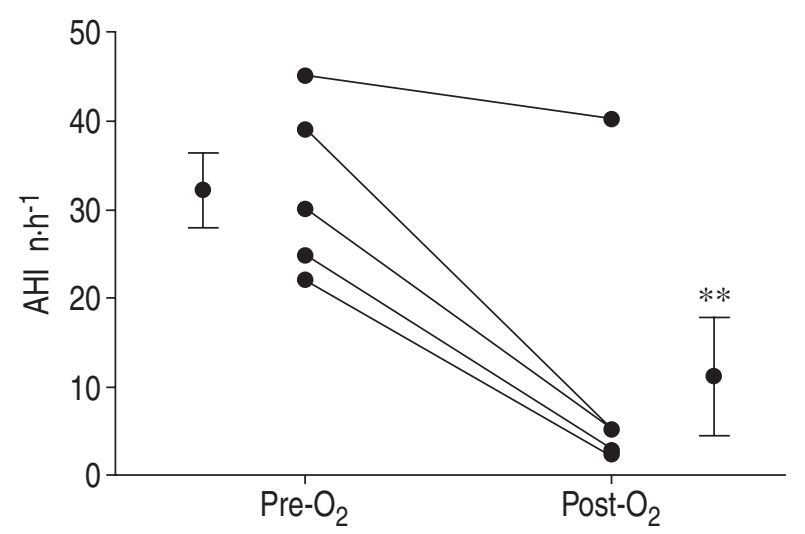

Fig. 2.-Effects of nasal oxygen administration on the apnoea/ hypopnoea index (AHI) in five patients with primary pulmonary hypertension and periodic breathing. Data are presented as individual values and as mean \pm SEM before and after nasal oxygen $\left(\mathrm{O}_{2}\right)$.**: $\mathrm{p}<0.01$.
On average, the patients with PB had more severe hypoxaemia and haemodynamic impairment than those without $\mathrm{PB} . \mathrm{O}_{2}$ administration during sleep led to reversal of $\mathrm{PB}$ in the majority of affected patients.

\section{Pathogenetic mechanisms of periodic breathing in primary pulmonary hypertension}

PB in PPH may result from similar pathophysiological mechanisms as CSR in CHF. First, prolonged circulation time due to low $\mathrm{CO}$ might lead to $\mathrm{PB}$ in PPH because only patients with severe reduction of cardiac performance showed sleep-disordered breathing. Second, it is probable that hypoxia plays a role in the development of PB in PPH by stimulating peripheral chemoreceptors as suggested by the more severe arterial hypoxaemia in the patients with $\mathrm{PB}$ and by the efficacy of nocturnal nasal $\mathrm{O}_{2}$ supplementation. Marked hypocapnia was present in the patients studied, although, no significant difference in the $\mathrm{Pa}_{1} \mathrm{CO}_{2}$ levels between patients with and without PB was found. Nevertheless, hypocapnia as a pathogenetic factor in PB associated with $\mathrm{PPH}$ cannot be excluded since the number of patients studied was relatively small.

Changes in chemosensitivity might also contribute to the emergence of PB in PPH. As the patients with $\mathrm{PB}$ had a similar degree of hypocapnia at a lower level of $\mathrm{Pa}, \mathrm{O}_{2}$, one might speculate that they had a lower hypoxic drive than those patients without PB. Theoretically, a decreased hypoxic drive could promote and/or prolong apnoeas by delaying the onset of hyperventilatory phases in PB. However, it would have been impossible to perform tests of hypoxic sensitivity in these severely hypoxic subjects.

A final point for consideration is the individual level of pulmonary vasoreactivity to alveolar hypoxia, i.e. the strength of the Euler-Liljestrand reflex. It is possible that those patients with more severe hypoxic pulmonary vasoconstriction and ventilation-perfusion mismatching are more prone to developing sleepdisordered breathing. The authors suggest that the lower $\mathrm{Pa}, \mathrm{O}_{2}$ in the patients with $\mathrm{PB}$ was primarily the consequence of more severely depressed right ventricular function. However, hypoxia by itself could have led to more pronounced pulmonary hypertension and thereby to a prolonged circulation time. Thus, a self-perpetuating vicious circle might be established in PPH which finally leads to the development of PB.

\section{Therapy of periodic breathing in primary pulmonary hypertension}

Administration of nasal $\mathrm{O}_{2}$ significantly reduced or even abolished PB in PPH. This finding parallels the observation that CSR in CHF can be successfully treated by the breathing of $\mathrm{O}_{2}[23,24]$. The beneficial effect of $\mathrm{O}_{2}$ was most probably related to the correction of arterial hypoxaemia in patients with $\mathrm{PB}$. 


\section{Clinical significance of periodic breathing in primary pulmonary hypertension}

The clinical significance of $\mathrm{PB}$ in $\mathrm{PPH}$ remains to be defined. Only two of the six patients with nocturnal PB complained of sleep-related symptoms. Correspondingly, a relatively low overall number of apnoea-related arousals and almost normal ESS scores were found in the subjects. To reach a firm conclusion concerning this question, a larger number of patients need to be studied.

However, apart from disrupting normal sleep it might well be possible that PB contributes to worsening of pulmonary hypertension as the apnoeaassociated hypoxia could trigger further vasoconstriction of the pulmonary vessels. Thus, PB in PPH might not only constitute an adverse prognostic sign, as is known for CSR in CHF [25-27], but it may also contribute to the further progression of the disease.

\section{Limitations of the study}

As already stated, a major limitation of the present study was the relatively small number of subjects studied. Furthermore, there was no control group. However, given the low prevalence of significant PB in a younger population, the finding that $30 \%$ of patients with PPH showed PB cannot be explained by chance. A final point of criticism concerns the method of measuring ventilatory flow. To monitor flow, oronasal thermistors were employed. It is well known, that other methods are more accurate at detecting apnoeas or hypopnoeas and in differentiating between central and obstructive events. These include recordings from oesophageal balloons, nasal prongs or the measurement of the pulse transit time [28, 29]. Unfortunately, this methodology was either not applicable in the patients studied (oesophageal probes) or not yet available in the sleep laboratory at the time of the investigation (nasal prongs, pulse transit time). However, the authors believe that the use of thermistors did not lead to extensive misclassification of sleepdisordered breathing in the patients, as they showed typical waxing and waning of ventilation between hypopnoeas/apnoeas.

To conclude, the occurrence of periodic breathing in patients with severe primary pulmonary hypertension and its reversal by nocturnal nasal oxygen, was described for the first time. The clinical and prognostic implications of periodic breathing in primary pulmonary hypertension remain to be determined by future studies enrolling larger numbers of patients.

\section{References}

1. Gaine SP, Rubin LJ. Primary pulmonary hypertension. Lancet 1998; 352: 719-725.

2. Rich S. Primary Pulmonary Hypertension. Executive Summary from the World Symposium. Geneva, World Health Organisation, 1998.
3. Kneussl MP, Lang IM, Brenot FP. Medical management of primary pulmonary hypertension. Eur Respir $J$ 1996; 9: 2401-2409.

4. Sandoval J, Gaspar J, Pulido T, et al. Graded balloon dilation atrial septostomy in severe primary pulmonary hypertension. A therapeutic alternative for patients nonresponsive to vasodilator treatment. J Am Coll Cardiol 1998; 32: 297-304.

5. Bando K, Armitage JM, Paradis IL, et al. Indications for and results of single, bilateral and heart-lung transplantation for pulmonary hypertension. J Thorac Cardiovasc Surg 1994; 108: 1056-1065.

6. De Backer WA. Central sleep apnoea, pathogenesis and treatment: an overview and perspective. Eur Respir J 1995; 8: 1372-1383.

7. Javaheri S, Parker TJ, Wexler L, et al. Occult sleepdisordered breathing in stable congestive heart failure. Ann Intern Med 1995; 122: 487-492.

8. Javaheri S, Parker TJ, Liming JD, et al. Sleep apnea in 81 ambulatory male patients with stable heart failure. Types and their prevalences, consequences and presentations. Circulation 1998; 97: 2154-2159.

9. Wuyam B, Pepin JL, Tremel F, Levy P. Pathophysiology of central sleep apnea syndrome. Sleep 2000; 23: Suppl. 4, S213-S219.

10. Pryor WW. Cheyne-Stokes respiration in patients with cardiac enlargement and prolonged circulation time. Circulation 1951; 14: 233-238.

11. Chapman KR, Bruce EN, Gothe B, Cherniack NS. Possible mechanisms of periodic breathing during sleep. J Appl Physiol 1988; 64: 1000-1008.

12. Fanfulla F, Mortara A, Maestri R, et al. The development of hyperventilation in patients with chronic heart failure and Cheyne-Stokes Respiration - a possible role of chronic hypoxia. Chest 1998; 114: 1083-1090.

13. Naughton M, Benard D, Tam A, Rutherford R, Bradley TD. Role of hyperventilation in the pathogenesis of central sleep apnea in patients with congestive heart failure. Am Rev Respir Dis 1993; 148: $330-338$.

14. Hanly P, Zuberi N, Gray R. Pathogenesis of CheyneStokes respiration in patients with congestive heart failure : relationship to arterial $\mathrm{PCO}_{2}$. Chest 1993; 104: 1079-1084.

15. Javaheri S. A mechanism of central sleep apnea in patients with heart failure. $N$ Engl J Med 1999; 341: 949-954.

16. Cherniack NS, Longobardo GS. Cheyne-Stokes respiration : an instability in physiologic control. $N$ Engl J Med 1973; 288: 952-957.

17. Olschewski H, Walmrath D, Schermuly R, Ghofrani A, Grimminger F, Seeger W. Aerosolized prostacyclin and iloprost in severe pulmonary hypertension. Ann Intern Med 1996; 124: 820-824.

18. Olschewski H, Ghofrani HA, Schmehl $\mathrm{T}$, et al. Inhaled iloprost to treat severe pulmonary hypertension. Ann Intern Med 2000; 132: 435-443.

19. Hoeper MM, Olschewski H, Ghofrani HA, et al. A comparison of the acute hemodynamic effects of inhaled nitric oxide and aerosolized iloprost in primary pulmonary hypertension. German PPH study group. J Am Coll Cardiol 2000; 35: 176-182.

20. Johns MW. A new method of measuring daytime sleepiness: the Epworth Sleepiness Scale. Sleep 1991; 14: $540-545$.

21. Rechtschaffen A, Kales A. A manual of standardized terminology, techniques and scoring system for sleep 
stages of human subjects. NIH publication no. 204. Maryland, USA, National Institute of Health in Bethesda, 1968.

22. American Sleep Disorders Association (ASDA) Report. EEG arousals: scoring rules and examples. A preliminary report from the Sleep Disorders Atlas task of the American Sleep Disorders Association. Sleep 1992; 15: 174-184.

23. Hanly P, Milar TW, Steljes DG, Baert R, Frais MA, Kryger MH. The effect of oxygen on respiration and sleep in patients with congestive heart failure. Ann Intern Med 1989; 111: 777-782.

24. Andreas S, Clemens C, Sandholzer H, Figulla HR, Kreuzer H. Improvement of exercise capacity with treatment of Cheyne-Stokes respiration in patients with congestive heart failure. J Am Coll Cardiol 1996; 27: 1486-1490.

25. Hanly P, Zuberi-Khokhar NS. Increased mortality associated with Cheyne-Stokes respiration in patients with congestive heart failure. Am J Respir Crit Care Med 1996; 153: 272-276.

26. Andreas S, Hagenah G, Möller C, Werner GS, Kreuzer H. Cheyne-Stokes respiration and prognosis in congestive heart failure. Am J Cardiol 1996; 78 : $1260-1264$.

27. Lanfranchi PA, Braghiroli A, Bosimini E, et al. Prognostic value of nocturnal Cheyne-Stokes respiration in chronic heart failure. Circulation 1999; 99: 1435-1440.

28. American Sleep Disorders Association (ASDA) Report. Sleep-related breathing disorders in adults: recommmendations for syndrome defintion and measurement techniques in clinical research. Sleep 1999; 22: 667-689.

29. Argod J, Pepin JL, Levy P. Differentiating obstructive and central sleep respiratory events through pulse transit time. Am J Respir Crit Care Med 1998; 158: $1778-1783$. 